shop is equipped with photocopying apparatus. Off the Main Library, on the first floor, there is a small room for storing and reading microfilms. On the second floor there are the main files of the Records and Reports Section, the index room and the collection of British and foreign patent specifications.

\section{ENERGY VALUE OF FOOD}

$\mathrm{T}^{\mathrm{s}}$ determine the number of calories that a known weight of food will give when it is burned in a bomb calorimeter is relatively simple; but to assess accurately the number of calories that the animal body can derive from that food presents several problems which have not yet been satisfactorily solved. The subject was discussed at a symposium arranged by the Scottish Group of the Nutrition Society and held at the Hannah Dairy Research Institute, Kirkhill, Ayr, on April 30. The morning session was devoted to methods of assessing the energy of feeding-stuffs for animals, and the afternoon session to the problem as it concerns food for man. At intervals during the day some of the work in progress at the Hannah Institute on the production and emission of heat by farm animals was demonstrated.

In introducing the subject the chairman, Prof. R. C. Garry (University of Glasgow), stressed the danger of regarding food simply as though it were fuel for a machine. Food is much more than fuel, and the animal body much more than a machine. Food has to build, repair and maintain the fabric of the body as well as supply it with energy for work, and the body, unlike the machine, processes its fuel in diges. tion, absorption and metabolism. The content of minerals, vitamins and other substances present may all affect the energy value of the food by influencing the well-being of the animal, and in man the matter is still more complicated since social habit, beliefs and prejudices may all play a part. The chemistry of a foodstuff must be thoroughly understood : in time the biochemical processes by which energy is liberated from it will be elucidated; but it will still be essential to consider the living animal as a biological entity.

The first paper of the morning session was a joint communication by K. L. Blaxter and N. McC. Graham, who first dealt briefly with the history of methods of evaluating foods as sources of energy for livestock. They pointed out that reliable values are needed for planning livestock production both at farm and at national level, since on such values depend in large measure the animal product output of farming as a whole and estimations of the quantities of feedingstuffs that must be imported. The second point they made was that measures of the energy value of foods are biological measures and cannot be expected to have the precision usually associated with the physical term 'calories' in which they are presented. Their statement that the efficiency of an animal in utilizing its food necessarily influences the nutritive value of the food it consumes emphasized this point, and was a theme that recurred time and again during the subsequent discussions.

Referring to the different ways in which the energy value of food for cattle is expressed, Blaxter and Graham emphasized the fact that, in order to estimate the value in terms of body storage of energy or in terms of energy transference to milk or eggs or its utilization for work, it is necessary to talse into account the heat production incidental to the consumption of the food. For this reason the term 'net energy' or 'starch equivalent', as it is termed in Britain, which takes this heat production into account, is superior to expressions of energy value in terms of 'digested energy' or 'metabolizable energy'. Methods of determining net energy were then considered, and slides were shown illustrating the various types of respiration calorimeter in use in different parts of the world. The difficulties involved in interpreting the older calorimetric observations made with cattle and sheep, and indeed those at present being made by Blaxter and Graham at the Hannah Institute, were then considered. The effect of plane of nutrition and the type of basal ration used was discussed, and the fact that very small analytical and instrumentel errors become greatly magnified by the very nature of the differential methods of computing the results was emphasized. Blaxter and Graham showed that, though well-known text-books and feeding-stuff tables quote energy values of some 250-300 foods, sixty years of work at Möckern experimental station in Germany, where almost all this work has been done, deal with but thirty-seven foods in seventy one experiments. Most of the values in the tables are therefore computed values, and recent work has shown that the accuracy of these estimations is frequently very low. Finally, Blaxter and Graham deplored the tendency of workers in this field during the past fifty years-admittedly with a few exceptions-to become involved in many points of minor importance and to spend much time on what is nothing more than arithmetical re-expression of the results obtained by Kühn, Kellner and Armsby without contributing in any way to a deeper knowledge of the subject. They regard it as imperative that an end should be put to recalculating Kellner's results of 1900-5 and that emphasis should be placed on new experiments carried out in the light of modern knowledge of intermediary metabolism and with modern equipment.

The discussion was continued in a second paper by Dr. J. C. D. Hutchinson (Poultry Research Centre, Edinburgh), who dealt with the reasons why there has been so little progress in assessing the energy value of feeding-stuffs in spite of the great scientific, economic and practical importance of the subject. He referred to the great difficulties involved and the slowness of this type of work, and cited experience with the Danish calorimeter for cattle with which he is personally acquainted, where the output over a long period averages one result per worker per year. Dr. Hutchinson referred to some ways in which a greater output could be obtained-by adopting more automatic methods of measuring heat loss, by dispensing with the necessity of simultaneous estimates of carbon, nitrogen and energy retention and possibly by using methods involving carcase analysis or bodywater determinations. $\mathrm{H}_{\theta}$ agreed with Blaxter and Graham that a more fundamental approach with less of the empiricism that has necessarily characterized the earlier work would prove most profitable in the future.

In the afternoon session Dr. E. M. Widdowson (University of Cambridge) mentioned that, until the Second World War, the energy values of food for man appeared to be of interest chiefly to compilers of food composition tables; but early in the War it was found that calorie calculations made on the two sides of the Atlantic did not agree, and this led to a better realization of the great practical importance of the subject. Dr. Widdowson discussed several tables of food composition published during the past fifty 
years and stressed that, although the methods of computation vary considerably for different tables, none of them appears to be correct. All are based on work done half a century ago in Germany by Rubner and in the United States by Atwater, who had been a pupil of Rubner. Both these early pioneers measured the intakes of protein, fat, carbohydrate and calories of people on different diets and estimated the calories lost in the frees and urine. From their results they calculated the energy values of individual foods and of mixed diets. In 1899 Atwater and Bryant concluded that protein and carbohydrate each give 4.0 kcal./gm. of total nutrients, and fat $8.9 \mathrm{kcal} . / \mathrm{gm}$. ; and yet a few years later when they compiled tables of food values for the composition of several thousand foodstuffs, they used Rubner's earlier figures of $4 \cdot 1$ for protein and carbohydrate and $9 \cdot 3$ for fat-a strange inconsistency which they did not explain and which was the forerunner of many others by later compilers of food tables. Indeed, throughout the years as one error was corrected another appeared to creep in. Even as recently as 1947 the committee on calorie conversion factors and food composition tables of the United Nations Food and Agriculture Organization, in calculating the calories per gram of ingested protein, failed to apply properly a simple correction factor for the amount of unoxidized material excreted in the urine, and thus, while improving some portions of the general computation, introduced a new error in another portion.

Towards the end of her paper Dr. Widdowson dwelt on the great need for further experiments with mixed diets more typical of those eaten to-day than were the diets studied by Atwater. She also stressed the need for experiments to be done with larger numbers of people so that more information can be obtained regarding the sort of variation that normally exists between individuals in the number of calories they obtain from their food. She referred briefly to the need for evolving methods by which the physiological energy value of food in infancy and during growth can be assessed. She readily admitted that many mistakes have been made in computing the energy values of human foods; but endeavoured to console herself and those present by recalling that he who makes no mistakes rarely makes anythingcertainly not food tables.

The second paper of the afternoon session was given by Miss $D$. F. Hollingsworth (Ministry of Agriculture, Fisheries and Food), who carried the general problem to its next stage by discussing the difficultios which are encountered in interpreting tables of food composition and in using them to estimate the energy value of human diets. For example, before the energy values given in tables can be applied in practice it is essential to consider how much of the purchased food is edible, how much water it contains, how much is lost in cooking and serving, and, as Miss M. Andross pointed out later in the discussion, how much is left as waste on the plate. To take one example, the moisture content of flour in food tables is usually assumed to be 12 per cent whereas in Britain for other purposes it is more normally taken as 15 per cent; this leads to a difference of roughly 3 per cent in the calculated energy value of the flour. Again, the fat content of meat can vary over a very wide range, and this can have a marked effect on the energy value computed for it. With made-up dishes the problems become still more involved, and in estimating requirements at an international level further complications arise when figures, which have been computed for British food supplies, are used for estimating the requirements of other countries where higher proportions of the total energy of the diet may be supplied by carbohydrates.

The four papers and the subsequent discussion achieved what was no doubt one of the main objects of the symposium, namely, to bring out some of the numerous difficulties that arise when attempts are made to assess accurately the energy values of foods, and to indicate some of the numerous problems that still wait to be solved by chemist, biochemist, physiologist and dietitian, as well as by those whose difficult duty it is to consider the general subject of world food supplies, their economics and distribution. J. A. B. SMITH

\section{CHEMICAL ASPECTS OF SEMICONDUCTORS}

A HALF-DAY symposium on "Chemical Aspects of Semiconductors" was held in the Chemistry Department of the University of Reading on March 26. The meeting, which attracted a gathering of some two hundred, was arranged by Dr. P. F. Holt (Reading) on behalf of the London Section of the Royal Institute of Chemistry. The chair was taken by Dr. F. S. Stone (Bristol). The aim of the symposium was to bring to the attention of chemists some of the problems of a chemical nature arising in the semiconductor field. The rapid developments in the technology of semiconducting materials which have taken place during the past ten years have only been achieved by close co-operation between the chemist and the physicist, and it is important that from time to time the current chemical problems in this predominantly physical field should be presented in a chemical forum. There is, moreover, a growing awareness among chemists of the contribution which semiconductors can make to fundamental studies on essentially chemical problems, such as adsorption and chemical bonding in solids, and this factor no doubt added to the general interest which the meeting aroused.

Since many of those present were not specialists in the semiconductor field, the main contributions were preceded by some introductory remarks on semiconductors, given by Dr. F. S. Stone. After outlining the principles underlying intrinsic and impurity semiconductivity, Dr. Stone dealt briefly with the rectifying and transistor action of germanium. In reviewing the chemical aspects, he stressed the importance of purification and standardization of materials. The significance of adsorption of active gases and vapours in creating a space charge at semiconductor surfaces was also emphasized, and attention was directed to the fact that very little fundamental work has so far appeared on adsorption at silicon and germanium surfaces.

The first of the more specialized papers was read by Mr. I. M. Ross (Services Electronics Research Laboratory, Baldock), who reviewed work on intermetallic semiconductors. Useful as silicon and germanium are for crystal-valve applications, their characteristics in respect of the combination of carrier mobility and separation between the valence and conduction bands are not entirely satisfactory. For other applications, such as photo-devices, quite different characteristics may be required. Interest has therefore turned to the closest analogues of 